Trab. Ling. Aplic., Campinas, 44(1): 89-95, Jan./Jun. 2005

\title{
O IMAGINÁRIO (COLONIAL) NO ENSINO DE ALEMÃO COMO LÍNGUA ESTRANGEIRA NO BRASIL
}

\author{
RUTH BOHUNOVSKY ${ }^{1}$ \\ (UNICAMP)
}

\begin{abstract}
RESUMO
Este artigo discute o papel da ideologia no ensino de alemão como língua estrangeira no Brasil e aborda questões relacionadas a interrelação linguagem, história e ideologia no material didático tradicional para o ensino de alemão como língua estrangeira.

Palavras-chave: ideologia, ensino, alemão como língua estrangeira.
\end{abstract}

\begin{abstract}
The article discusses the role of ideology in the teaching of german as foreign language in Brazil and tackles questions related to the interrelationship among language, history and ideology in traditional teaching material for the teaching of german as foreign language.

Key-words: ideology, teaching, german as foreign language.
\end{abstract}

Neste artigo, desenvolvo algumas reflexões sobre o papel do imaginário no ensino de alemão como língua estrangeira no Brasil. A argumentação está fundamentada em duas premissas básicas. A primeira é a de que qualquer contato entre dois sujeitos - por exemplo, um brasileiro e um alemão/austríaco/suíço - será sempre marcado pelos imaginários que esses sujeitos trazem, tanto em relação a si mesmos quanto em relação ao outro. E a segunda, de que um dos objetivos do ensino de alemão como língua estrangeira deve ser a preparação dos aprendizes exatamente para um contato com os falantes nativos da língua-alvo. Esses aspectos já sugerem a pertinência de uma discussão aprofundada acerca desses possíveis imaginários, no contexto da Lingüística Aplicada.

O campo teórico que oferece os subsídios teóricos necessários para a reflexão aqui proposta é a "Lingüística Aplicada Crítica", conforme definida por Alastair Pennycook (2003). Em constante diálogo com campos acadêmicos como a teoria crítica, o feminismo, o pós-colonialismo, o pós-estruturalismo e a pedagogia anti-racista (ibid.: 31), essa linha de pensamento teria aberto "todo um novo leque de questões e considerações", onde temas como "identidade", ou "a reprodução daquilo que caracteriza o Outro", que "até agora não

\footnotetext{
${ }^{1}$ A autora é pós-doutoranda no IEL, UNICAMP, sob supervisão da Profa. Dra. Carmen Zink Bolognini. O projeto de pós-doutorado "Alemão para brasileiros: (re)vendo imagens" está sendo apoiado pela FAPESP (processo número 03/13796-6).
} 
[tinham] sido considerados como pertinentes à Lingüística Aplicada" (ibid.), passam a ocupar um lugar de destaque. Enfatizando o trabalho de B. Dendrinos (1992), Pennycook observa que, no contexto da Lingüística Aplicada Crítica, "há uma crescente quantidade de análise crítica muito necessária sobre os interesses e ideologias subjacentes à construção e à interpretação dos livros didáticos" (2003: 40). Entretanto, no Brasil, parece haver uma lacuna nesse sentido na área de ensino de alemão como língua estrangeira, e é justamente para essa lacuna que o presente trabalho visa chamar a atenção.

A Lingüística Aplicada Crítica parte de uma visão não essencialista dos valores da modernidade, o que a coloca nas proximidades da pós-modernidade (Pennycook, 1994: 57). De acordo com Pennycook, o maior desafio para essa vertente da lingüística seria "entender as relações entre conceitos de sociedade, ideologia, capitalismo global, colonialismo, educação, gênero, racismo, sexualidade, classe e os discursos da sala de aula" (2003: 26). A partir disso, pretende-se desenvolver uma concepção de Lingüística Aplicada "mais politicamente responsável" (ibid.: 28), visando oferecer aos aprendizes não apenas informações sobre o contexto sociocultural, político, ideológico e histórico do(s) país(es) da língua-alvo e dos seus falantes, mas também encorajá-los a desenvolver um olhar mais crítico em relação aos imaginários já "naturalizados" (ibid.: 29) em favor de uma certa ideologia ${ }^{2}$. De acordo com Pennycook e vários outros autores (nem todos da área da Lingüística ${ }^{3}$ ), esses imaginários encontram-se, muitas vezes, enraizados num discurso colonial.

Como todas as tendências que partem de uma perspectiva "discursivadesconstrutivista" (Maria J. Coracini e Ernesto Sérgio Bertoldo, 2003: 13) ${ }^{4}$ acerca de qualquer manifestação lingüística, a Lingüística Aplicada Crítica recusa qualquer teoria que reduza a linguagem a um sistema de comunicação de significados supostamente estáveis, intrínsecos ao texto, independentes de seu contexto, e suscetíveis de serem "resgatados" por um leitor. Além disso, essa vertente dos estudos lingüísticos defende uma concepção de sujeito influenciada pela psicanálise e se opõe ao sujeito cartesiano, isto é, trabalha com um sujeito "descentrado, clivado, múltiplo, atravessado pelo inconsciente" (Coracini, 2003: 13). Assim, no contexto da Lingüística Aplicada Crítica, um texto pode apenas sugerir uma determinada leitura, mas quem definirá uma certa interpretação será sempre o sujeito em sua determinação ideológica-histórica e em sua singularidade. Em suma, deve-se sempre lembrar que, de acordo com a referida corrente teórica, qualquer tendência reducionista

${ }^{2}$ Em relação ao conceito de ideologia, este artigo não se orienta pela tradição epistemológica que relaciona a ideologia a idéias como ilusão, distorção ou mistificação de uma suposta realidade (p. ex., Gottfried W. F. Hegel, Karl Marx, George Lúkacs), nem pela tradição sociológica que se interessa pela função das idéias na vida social (cf. Terry Eagleton, 1997: 16). Ecoando John B. Thompson, entende-se por ideologia "os modos pelos quais o significado (ou a significação) contribui para se manter as relações de dominação" (1984, apud Eagleton, 1997: 19).

${ }^{3}$ Cf., por exemplo, Edward Said (1999).

${ }^{4}$ Friedrich Nietzsche, Michel Foucault e Jacques Derrida destacam-se como os pensadores mais influentes para essa perspectiva "discursiva-desconstrutivista". Para uma discussão sobre a concepção de signo nesse contexto teórico-filosófico, cf., por exemplo, Rosemary Arrojo (1992). 
acerca dos conceitos de interpretação, discurso, imaginário ou ideologia deve ser vista como não-pertinente.

Ao se admitir os textos apresentados em material didático como interpretações, ou como discurso, abre-se uma brecha para se discutir o seu comprometimento ideológico. Sobre esse tema, Coracini tem desenvolvido ricas reflexões teóricas ${ }^{5}$. No que concerne ao material de ensino de alemão como língua estrangeira, quem deu início à discussão sobre os aspectos ideológicos desses textos foi Carmen Zink Bolognini. Com base no aparelho teórico da análise de discurso de linha francesa ${ }^{6}$, a autora aborda, ainda que apenas tangencialmente, o livro Themen Neu e defende que esse material didático ajuda a manter, estabilizar e silenciar as relações hierárquicas de poder que existem entre o Brasil e a Alemanha ${ }^{7}$ desde os inícios da colonização européia até hoje (1996: 174-178).

Bolognini parte do pressuposto de que os lugares de interlocução - isto é, o lugar que dois sujeitos fazem "de seu próprio lugar e do lugar do outro" (Pêcheux, 1969: 82) - que marcam as relações entre brasileiros e alemães até hoje estão ancorados na história das relações entre os dois países (Bolognini, 1996: 22). Assim, ao se descrever a Alemanha apenas como berço de grandes realizações culturais (ibid.: 172), como um país desenvolvido, com tecnologia avançada, cujos produtos são objetos de consumo de outros países (ibid.: 141), ou como um lugar onde os conflitos, quando surgem, são sempre resolvidos (ibid.: 177) - como acontece no material didático analisado por Bolognini -, contribuir-se-ia para estabilizar efeitos de sentido produzidos durante os últimos séculos em favor da manutenção da suposta posição superior da Europa frente ao Brasil. Tal discurso sugeriria, conforme defende Bolognini, uma postura ideológica que acabaria reforçando o lugar de interlocução supostamente inferior do brasileiro em relação ao alemão.

A partir da análise imagológica Retratos de Brasil (1996), de Celestes H. M. R. de Sousa, fica evidente que o tipo de imaginário sobre a Alemanha (e sobre o Brasil), detectado por Bolognini em material didático para o ensino de alemão, reflete a tradição literária alemã durante os últimos 500 anos. De acordo com Sousa, na literatura alemã existiriam "duas perspectivas distintas" acerca do Brasil (1996: 211). A primeira consideraria este país e a Alemanha como "realidades idênticas", negando ao Brasil sua "especificidade". Já a segunda perspectiva entenderia os dois referidos países em termos de "superioridade" e "inferioridade", o que redundaria, novamente, em um etnocentrismo (ibid.). A autora conclui que "a imagem [geralmente difundida na literatura alemã] do Brasil, em essência, ainda se encontra vinculada a fantasias referentes ao continente recém-descoberto, isto é, a mitos da Conquista" (ibid.).

\footnotetext{
${ }^{5}$ Cf., por exemplo, Coracini (1999; 2003).

${ }^{6}$ Bolognini baseia-se, sobretudo, em Eni P. Orlandi (1988; 1990; 1993).

${ }^{7}$ Bolognini refere-se exclusivamente à Alemanha, mas a mesma argumentação poderia ser desenvolvida em relação aos outros países de língua alemã, isto é, a Áustria e a Suíça.

${ }^{8} \mathrm{O}$ fato de a Alemanha, a Áustria e a Suíça não terem participado ativamente na colonização do Brasil não significa que o discurso dominante nesses países não tenha incorporado as características geralmente associadas ao discurso colonial. Para discussões mais aprofundadas sobre esse tema, cf., por exemplo, Ana Maria de M. Belluzzo (2000), Celeste H. M. R. de Sousa (1996).
} 
Essa avaliação do imaginário em relação ao Brasil na literatura alemã está em consonância, por sua vez, com a argumentação desenvolvida por Eni P. Orlandi (1990). Conforme argumenta essa autora, o discurso historiográfico europeu teria concedido ao Brasil apenas a posição de uma cópia da Europa que, com mais ou menos sucesso, teria conseguido se aproximar do seu "ideal". Ou seja, o Brasil nunca teria sido muito mais do que uma parte da história européia, os sentidos produzidos acerca desse país teriam favorecido a manutenção das relações hierárquicas entre a (ex)colônia e a Europa. Conseqüentemente, aos brasileiros tem sido concedido apenas o direito de ter "particularidades, singularidades e peculiaridades culturais" (Orlandi, 1990: 15), mas não uma história própria, uma interpretação peculiar da História.

A validade do discurso colonial começou a ser repensada no contexto do póscolonialismo - que trouxe a tentativa de decompor a hierarquia de culturas "superiores" e "inferiores", de politizar a estética e cultura e de visibilizar os mecanismos de demonstração de poder nas imagens e falas coloniais. Na Lingüística Aplicada Crítica, essas discussões têm se dirigido aos discursos sobre e na sala de aula.

Um exemplo, que pode aqui ilustrar a persistência de um imaginário marcado pelo discurso colonial acerca do Brasil em material didático para o ensino de alemão, é uma passagem de Die Suche (Textbuch 2), na qual uma personagem brasileira, que ocupa um lugar importante na história que guia o livro todo, é apresentada como uma mulher especialmente bonita - parecendo uma "fada, uma princesa" (2002: 36) - cuja marca mais característica seria, conforme ela mesma explica, um papagaio que leva nas costas (ibid.: 15). Herdeira de seu padrasto milionário, ela é acompanhada por um senhor vestido num estilo que lembra os filmes sobre a época colonial (ibid.: 37). Além disso, a personagem é apresentada como filha de uma brasileira "de nome Maria" (ibid.: 47) que, quando jovem, era uma "moça muito linda" (ibid.) que teve um romance amoroso, uma "aventura de férias" (ibid.: 15), com um alemão que a conquistou por ser "alto, esbelto" e por saber dançar samba "fantasticamente" (ibid.: 47). No mesmo livro, a personagem principal, o alemão Helmut Schmidt, destaca que associa com o Brasil apenas palavras como "samba", "carnaval", "favelas" e a "floresta da Amazônia" (ibid.: 36). Como já indicam essas poucas citações, o referido material didático sugere uma interpretação que estabiliza certos efeitos de sentido que têm norteado a história sobre o Brasil escrita por europeus. Ou seja, os brasileiros são caracterizados, na maioria das vezes, por uma grande sensualidade, por sua liberdade sexual e pelo estreito contato com a natureza exótica do seu país, enquanto este permanece reduzido à exuberância da natureza. Cultural, social e economicamente, o Brasil aparece numa posição inferior àquela da Europa. Essa imagem não é nem contestada, nem problematizada, pelo discurso apresentado no material didático Die Suche.

Outro ponto que chama a atenção nos livros didáticos para o ensino de alemão como língua estrangeira ${ }^{9}$ é o caráter pouco crítico das discussões apresentadas acerca dos países de língua alemã - por exemplo, acerca da época nazista, de problemas de xenofobia, do

\footnotetext{
${ }^{9}$ A base para a argumentação aqui desenvolvida tem sido Themen Neu, Moment mal, Die Suche e Stufen. Essa escolha se deve à popularidade desses livros no ensino de alemão como língua estrangeira no Brasil.
} 
radicalismo político e do desemprego, para citar apenas pontos problemáticos da história mais recente. Aos resultados da prosperidade econômica das últimas décadas e aos avanços sociais e democráticos nos países de língua alemã, é dedicado muito espaço. Já os problemas atuais, ou passados, são apresentados de uma maneira pouco profunda e pouco crítica. À guisa de exemplo, pode-se mencionar que o tema da presença de estrangeiros na Alemanha ganha o nome de "convivência internacional" (Stufen I, Lektion 9). Ao mesmo tempo em que se enfoca criticamente a intolerância e os preconceitos (Stufen III, Lektion 23, 25; Moment Mal II, Lektion 24), personagens estrangeiros - por exemplo, um nigeriano e uma turca declaram nunca ter tido problemas com racismo (Stufen III, Lektion 25). Em outro momento, personagens estrangeiros referem-se à "intolerância", ou aos "mal-entendimentos", que sofrem, mas novamente são as iniciativas multi-culturais existentes nos países de língua alemã que merecem o maior destaque (Moment Mal II, Lektion 24). Quando é contada uma história conflituosa, onde os preconceitos levam à morte de alguns habitantes de um país - algo que ocorreu repetidamente na Alemanha nos anos 90 -, os personagens são animais (lobos e coelhos) e o lugar não é identificado (cf. Stufen III, 80). É certo que a interpretação sugerida pelos autores dos livros revela uma postura explicitamente anti-racista e tolerante em relação a diferenças culturais e étnicas. No entanto, não deve ser ignorado que isso não corresponde à maioria absoluta dos seus concidadãos. A história dos países de língua alemã não se limita a aspectos negativos, mas isso não justifica o silenciamento que ocorre sobre temas polêmicos e politicamente sensíveis, tanto do passado, quanto da atualidade, nos referidos livros didáticos.

O olhar muitas vezes ufanista sobre os referidos países que parece estar sendo sugerido pelos autores do material didático acima mencionado - um olhar que traz consigo a exclusão de informações e discussões que possam desafiá-lo - apresenta-se como "verdade", na tradição do discurso pedagógico em geral (cf. Coracini, 2003: 200). Não é deixado muito espaço para uma maior familiarização dos aprendizes com a diversidade dos contextos sócio-culturais, políticos e ideológicos nos quais se situam os falantes nativos de alemão. Sem dúvida, qualquer professor terá sempre a possibilidade de instigar os aprendizes a desenvolverem uma postura mais crítica ${ }^{10}$ - independentemente do material didático utilizado em sala de aula -, mas os textos apresentados não parecem sugerir tal leitura.

Sem pretender desacreditar o valor didático e informativo de livros como Themen Neu, Moment mal, Stufen e Die Suche, mas considerando o que foi exposto, parece ser possível argumentar que, atualmente, não existe um material que possa oferecer - aos aprendizes e professores interessados - uma base para se refletir criticamente sobre os diversos contextos ideológicos que, ao longo da história de contatos entre o Brasil e a Europa, têm marcado, e ainda marcam, qualquer relação entre um brasileiro e um alemão/austríaco/suíço ${ }^{11}$. Visto

\footnotetext{
${ }^{10}$ Não deve ser ignorado que existe material didático para o ensino de alemão como língua estrangeira que coloca em xeque o imaginário ufanista acerca da Alemanha como, por exemplo, a série de vídeos "Bildschirm". Porém, esse material não é concebido como base para um curso de alemão, mas apenas como material adicional, geralmente pouco utilizado em sala de aula.

${ }^{11} \mathrm{O}$ único material didático para o ensino de alemão como língua estrangeira publicado no Brasil segue a metodologia estruturalista e não aborda, explicitamente, as especificidades extralingüísticas do contato entre brasileiros e alemães/austrícos/suíços (Anke e Jörg Rautzenberg, 1978).
} 
que, no contexto do pós-colonialismo - e da Lingüística Aplicada Crítica - os esforços das pessoas de países antigamente colonizados se dirigem, cada vez mais, contra os resíduos do discurso colonial, justificar-se-ia certamente a elaboração de um material didático que compartilhe essa postura ideológica.

O interesse pelo tema aqui abordado justifica-se, também, por sua atualidade. Não apenas porque, com a passagem dos 500 anos da chamada "descoberta" do Brasil, se iniciaram discussões mais amplas sobre a história, colonização, identidade e os valores do país, mas também porque o tema do trabalho aqui proposto corresponde a dois interesses bastante comuns entre os profissionais da área de ensino de alemão como língua estrangeira: primeiro, o interesse em pesquisar mais aprofundadamente o papel da comunicação intercultural num contexto marcado pelo pensamento pós-colonial e, segundo, o interesse em estudar as especificidades das relações de contato estabelecidas entre membros de duas culturas específicas ${ }^{12}$.

De acordo com as premissas da Lingüística Aplicada Crítica, o interesse não seria estabelecer uma interpretação alternativa, ou absolutamente contrária daquela sugerida em livros como Themen Neu ou Stufen, mas primordialmente estimular os aprendizes a atentarem para os diversos discursos heterogêneos que necessariamente vão marcar o contato que estabelecerão com uma outra língua - discursos com maior ou menor poder político e com embasamentos ideológicos e interesses distintos. Fazendo referência a uma observação de Sousa, pode-se sintetizar a visão que fundamenta o presente artigo da seguinte maneira: estudar a imagem de um país e seus habitantes em livros didáticos constitui "um passo adiante" na "identificação e posterior desconstrução de estereótipos criados no correr dos séculos que, freqüentemente, ainda se agregam à imagem de determinados países e dificultam o bom relacionamento entre os povos" (1996: 16).

\section{REFERÊNCIAS BIBLIOGRÁFICAS}

ARROJO, R. (1992). O signo desconstruído: Implicações para a tradução, a leitura e o ensino. Campinas, SP: Pontes.

BELluZZO, A. M. de M. (2000). O Brasil dos viajantes. $3^{\text {a }}$ ed., São Paulo: Metalivros e Objetiva.

BOLOGNINI, C. Z. (1996). O lugar de interlocução de brasileiros e alemães na história de suas relações de contato. Tese (Doutorado em Lingüística) - Instituto de Estudos da Linguagem, Universidade Estadual de Campinas: Campinas, SP.

CORACINI, M. J. R. F. (org.). (1999). Interpretação, autoria e legitimação do livro didático: língua materna e língua estrangeira. Campinas, SP: Pontes.

, BERTOLDO, E. S. (orgs.). (2003). O desejo da teoria e a contingência da prática: discursos sobre e na sala de aula: língua materna e língua estrangeira. Campinas, SP: Mercado de Letras.

${ }^{12}$ Cf., por exemplo, as contribuições em X. Internationale Deutschlehrertagung: Tagungsbericht (1993: 129-139); XI. Deutschlehrertagung Amsterdam: Thesen der Sektionsbeiträge (1997: 31-60); IV Congresso brasileiro de professores de alemão (1999); XI Congresso da Associação Latino-americana de Estudos Germanísticos (2003). 
EAGELTON, T. (19970. Ideologia: uma introdução. Tradução de Luís Carlos Borges e Silvana Vieira. São Paulo: Unesp/Boitempo.

ORLANDI, E. P. (1988). Discurso e leitura. São Paulo: Cortez; Campinas, SP: Unicamp. . (1990). Terra à vista!: Discurso do confronto: Velho e novo mundo. São Paulo: Cortez; Campinas, SP: Unicamp. . (1993). As formas do silêncio. Campinas, SP: Unicamp.

PÊCHEUX, M. (1990). "Análise automática do discurso", In: GADET François e Hak Tony. Por uma análise automática do discurso: uma introdução à obra de Michel Pêcheux, Tradução de Bethania S. Mariani et. al. Campinas: Unicamp.

PENNYCOOK, A. (2003). “Lingüística Aplicada pós-ocidental”. In: CORACINI, Maria José R. J., BERTOLDO, Ernesto Sérgio (orgs.). O desejo da teoria e a contingência da prática: discursos sobre e na sala de aula: língua materna e língua estrangeira. Campinas, SP: Mercado de Letras. p. 21-60.

RAUTZENBERG, A. e J. (1978). Aufbaukurs Deutsch. $2^{\text {a }}$ ed. São Paulo: Pedagógica e Universitária Ltda..

SAID, E. (1999). Cultura e Imperialismo. Tradução de Denise Bottman. São Paulo: Companhia das Letras.

SOUSA, C. H. M. R. de. (1996). Retratos do Brasil: hetero-imagens literárias brasileiras. São Paulo: Arte \& Cultura. 